\title{
Effectiveness of Structured Teaching Programme on Knowledge and attitude regarding Menstrual Hygiene among Adolescent Girls.
}

${ }^{*} M s$. Suganya. $V$

\begin{abstract}
:
Objectives: To assess the Effectiveness of Structured Teaching Program on knowledge and attitude regarding Menstrual Hygiene among Adolescent girls in Rani Seethai Aachi Higher Secondary School, Chidambaram. Methodology: Materials and Methods: The research approach was quantitative research approach and the research design adopted was one group pretest posttest design. The study was conducted among VIII \& IX standard students of Rani Seethai Aachi Higher Secondary School, Chidambaram. The sample size was 5o, and the sampling technique adopted was convenient sampling technique. Results: The overall knowledge of the pretest and post test showed that $72 \%$ of the students had inadequate knowledge and after teaching $78 \%$ of students hadadequate knowledge. And over all attitude in pretest and post test showed 36\% had unfavorable attitude in pretest and 72\% had favorable attitude in posttest.
\end{abstract}

Key words : Knowledge, Attitude, Menstrual Hygiene and Adolescent Girls.

\section{INTRODUCTION}

India is home to the highest number of adolescents in the world. Healthy adolescent girls only produce healthy children for our nation. The term adolescence is derived from the Latin word "Adolescere" meaning to grow, to maturity. Adolescence is a period of transition from childhood to adulthood. It is characterized by rapid physical growth, significant physical, emotional, psychological and spiritual changes. Menstruation is a physiological phenomenon which is unique to females that begins in adolescence.
It is monthly uterine bleeding for 4-5 days coming regularly every 28 days. Normally females get 13 menses in a year and around 400 menses in her reproductive life. The first menstruation is termed as "menarche". The age of menarche is between 10- 16 years in India. A study conducted in Ranchi, India reported that $45.5 \%$ of the girls face social restrictions, majority of them were restricted in religious practices, wearing new clothes, cooking food, etc. Girl should have good menstrual hygiene practice during this period. 


\section{OBJECTIVES:}

- To assess the knowledge and attitude regarding Menstrual Hygiene among Adolescent girls

- To evaluate the effectiveness of Structured Teaching Programme on knowledge \& attitude regarding Menstrual Hygiene among Adolescent girls

- To find association between existing knowledge, attitude with demographic variables

\section{METHODOLOGY:}

Quantitative research approach with pre experimental (one group pre testpost test) design was adopted to assess the knowledge and attitude regarding Menstrual Hygiene 50

adolescents girls were selected by Convenient Sampling Technique at Rani Seethai Aachi Higher Secondary School, Chidambaram. Pre-test was conducted to 50 students and students were gathered in one class room and self-administered questionnaires were given to all students. The structured teaching programme on Menstrual hygiene was conducted for 45 minutes. Post-test was conducted after 7 days.

\section{RESULTS:}

Frequency and percentage of demographic Variables among the students

The findingshows the frequency and percentage distribution of samples according to demographic variables. Out of 50 student's father's occupation $2(4 \%)$ were unemployed. 25(50\%) were agriculture, 30\%(15) were business men and $16 \%(8)$ worked in Government. Regarding the mother's education $36 \%(18)$ were uneducated; but the majority $64 \%$ (32) were educated. It was found that $50 \%$ were getting less than Rs.3000 and 50\% were getting more than RS. 3000 as income per month. Regarding religion most of the student's 90\%(45) belonged to Hindu and 10\% (5) student's belonged to Christianity. Result showed that $58 \%(29)$ were living in Urban and $42 \%(21)$ were living in Rural area. Regarding family type 45(90\%) student's were in Nuclear family and only 5(10\%) student's were in joint family. Regarding sources of information,4(8\%), of student 's got information from Radio, 16(32\%) student's Received from television,11(22\%) of student's received information from book and 19(38\%) of student did not receive any information regarding menstrual hygiene.

Table 1: Frequency Distribution on Level of Knowledge among Students in Pre Test and Post Test

$\mathbf{N}=\mathbf{5 0}$

\begin{tabular}{|c|l|c|c|c|c|}
\hline \multirow{2}{*}{ S.No } & \multirow{2}{*}{ Level of knowledge } & \multicolumn{2}{|c|}{ Pre-test } & \multicolumn{2}{c|}{ Post-test } \\
\cline { 3 - 7 } & & No & Percentage & No & Percentage \\
\hline 1. & Inadequate knowledge(0-4) 30\% & 36 & $72 \%$ & 4 & $8 \%$ \\
\hline 2. & Moderately adequate knowledge(5-8)70\% & 10 & $20 \%$ & 7 & $14 \%$ \\
\hline 3. & Adequate knowledge(9-15) above $71 \%$ & 4 & $8 \%$ & 39 & $78 \%$ \\
\hline
\end{tabular}


Table 1: It showed that 36(72\%) students had inadequate knowledge in pre-test, but in post test $39(78 \%)$ of the students were reported to have adequate knowledge. It indicates that there was improvement in the level of knowledge in post-test compared with pre-test.

Table 2: Frequency Distribution on Level of Attitude of Student in Pre Test and Post Test

$\mathbf{N}=\mathbf{5 0}$

\begin{tabular}{|c|l|c|c|c|c|}
\hline \multirow{2}{*}{ S. no } & \multirow{2}{*}{ Level of attitude } & \multicolumn{2}{|c|}{ Pre-test } & \multicolumn{2}{c|}{ Post -test } \\
\cline { 3 - 6 } & & No & Percentage & No & Percentage \\
\hline 1. & Unfavourable attitude(0-2)-20\% & 18 & $36 \%$ & 1 & $2 \%$ \\
\hline 2. & Moderately favourable attitude(3-5) $30 \%$ & 28 & $56 \%$ & 13 & $26 \%$ \\
\hline 3. & Favourable attitude(6-8) 50\% & 4 & $8 \%$ & 36 & $72 \%$ \\
\hline
\end{tabular}

Table 2 showed that $18(36 \%)$ students had unfavorable attitude in pre-test but in post-test $36(72 \%)$ of the students had favorable attitude. It indicates that there was an improvement in the level of attitude in post-test compared to pre-test.

The association of knowledge on menstrual hygiene with selected demographic variables of the students revealed that Father occupation, mother educations were significantly influencing their knowledge on menstrual hygiene for the adolescence girls at $\mathrm{p}<0.033$.

Effectiveness of knowledge and attitude regarding menstrual hygiene among adolescent girls

$\mathrm{N}=\mathbf{5 0}$

\begin{tabular}{|c|c|c|c|}
\hline \multirow{2}{*}{ S.No } & \multirow{2}{*}{ Level of knowledge } & Pre-test & Post-test \\
\hline & & Percentage & Percentage \\
\hline 1. & Inadequate knowledge(0-4) 30\% & $72 \%$ & $8 \%$ \\
\hline 2. & Moderately adequate knowledge(5-8)70\% & $20 \%$ & $14 \%$ \\
\hline 3. & Adequate knowledge(9-15) above $71 \%$ & $8 \%$ & $78 \%$ \\
\hline 4. & Unfavourable attitude( $(0-2)-20 \%$ & $36 \%$ & $2 \%$ \\
\hline 5. & Moderately favourable attitude(3-5) 30\% & $56 \%$ & $26 \%$ \\
\hline 6. & Favourable attitude(6-8) 50\% & $8 \%$ & $72 \%$ \\
\hline
\end{tabular}

*P<o.o33 Level Significant

\section{DISCUSSION:}

This chapter deals with the discussion of the study with appropriate literature review, statistical analysis and finding of the study based on objectives of the study. The aim of the present study is to evaluate the effectiveness of structedteaching programme on Menstrual hygiene in the terms of knowledge, attitude among the adolescent girls in a selected school at Annamalainagar. 
Most of the studies also have stressed the importance of health education on menstrual hygiene to school girls and the involvement of teachers in it. The study finding shows that the structure teaching programme was effective in school girls. This type of education programme can bring about a change in knowledge, attitude and create awareness in promoting menstrualhygiene.

\section{CONCLUSION:}

The Government should conduct regular health care and health education programme to promote health among the adolescent girls through professional and non-Professional team.

\section{REFERENCE:}

6. Dutta D.C (2008), "Text book of obstetrics", $7^{\text {thed, calcutta }: \text { New central }}$ agency (P) ltd.

7. Hockenberry, J.M (2012), "Wong's Essentials of Pediatric Nursing", $7^{\text {th }}$ ed. Philadelphia. Elsevier.

8. Annamma Jacob (2005). A comprehensive textbook of midwifery, $2^{\text {nded, Jaypeebrothers medical }}$ publishers (P) ltd.

9. AH. Suryakanthab(2010), "Community Medicine With Recent Advances",

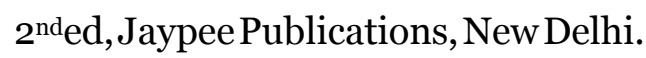

1. VC.PadubidriSnDaftary, Hawkins \&Bourne, (2011) "Shaw's Textbook OfGyenecology" $15^{\text {thed, }}$ Elsevier Publications, Mumbai.

2. Anusree P.C.1, Ardra Roy2, Aswathy B. Sara, Faseela VCM, Gincy(Jan. 2014) PIOSR Journal of Nursing and Health Science (IOSR-JNHS). e-ISSN: 23201959.p- ISSN: 2320-1940 Volume 3, Issue 1 Ver. IV, PP 55-60..

3. Ranjan Kumar Prusty.InternationalJournal o/MCH and AIDS (2013), Volume 2, Issue 1, Pages 103110 .INTERNATIONAL JOURNALo/MCH and AIDSISSN 2161-864X (Online)ISSN 2161-8674 (Print).

4. Subhash B. Thakre et al., 2011 October, Menstrual Hygiene www.jcdr.net1028 Journal of Clinical and Diagnostic Research. Vol-5(5): 1027-1033to their life processes and promoting their quality of life.

5. .TeklemariamGultie ,DestaHailu ,Yinag erWorkineh Published: September 30, 2014.,Age of Menarche and Knowledge about Menstrual Hygiene Management among Adolescent School Girls in Amhara Province, Ethiopia: DOI: 10. 1371/journal.pone.0108644

\section{MULTIPLE MYELOMA MNEMONIC: OLD CRAB}

MULTIPLE MYELOMA

OLD - Old Age

C - Calcium Elevated (Hypercalcemia)

$\mathbf{R}$ - Renal Failure

A - Anemia

B - Bone Lytic Lesions 